\title{
Bubbly-ice densification in ice sheets: II. Applications
}

\author{
Vladimir Ya. Lipenkov, ${ }^{1}$ Andrey N. Salamatin, ${ }^{2}$ Paul Duval ${ }^{3}$ \\ ${ }^{1}$ Arctic and Antarctic Research Institute, St. Petersburg 199397, Russia \\ ${ }^{2}$ Kazan State University, Kazan 420008, Russia \\ ${ }^{3}$ Laboratoire de Glaciologie et Géophysique de l'Environnement, 38402 Saint-Martin-d'Hères Cedex, France
}

\begin{abstract}
A mathematical model for simulating the densification of bubbly glacier ice is used to interpret the following experimental data from the Vostok (central Antarctica) ice core: two ice-porosity profiles obtained by independent methods and a bubblepressure profile obtained by direct measurements of air pressure within individual bubbles. The rheological properties of pure polycrystalline ice are deduced from the solution of the inverse problem. The model and the inferred ice-flow law are then validated, using porosity profiles from seven other ice cores drilled in Antarctica and Greenland, in the temperature range from $-55^{\circ}$ to $-20^{\circ} \mathrm{C}$. The following expression is adopted for the constitutive law:

$$
2 \dot{e}=\left(\tau / \mu_{1}+\tau^{\alpha} / \mu_{2}\right) \exp \left[Q\left(1 / T_{\mathrm{s}}-1 / T\right) / R_{\mathrm{s}}\right]
$$

where $\dot{e}$ and $\tau$ are the effective strain rate and stress, respectively, $\alpha$ is the creep exponent taken as $3.5, R_{\mathrm{s}}$ is the gas constant and $T\left(T_{\mathrm{s}}\right)$ is the temperature (standard temperature). The numerical values obtained for the "linear" and "non-linear" viscosities are: $\mu_{1}=2.9 \pm 1.3 \mathrm{MPa}$ year and $\mu_{2}=0.051 \pm 0.019 \mathrm{MPa}^{\alpha}$ year, and the apparent activation energy $Q$ is confirmed to be $60 \mathrm{~kJ} \mathrm{~mole}^{-1}$. The corresponding flow law is in good agreement with results of both mechanical tests and independent estimations based on the analysis of different natural phenomena associated with glacier-ice deformation. When the model is constrained by the porosity and bubble-pressure profiles from Vostok, the mean air content in Holocene ice is inferred to be about $0.088 \mathrm{~cm}^{3} \mathrm{~g}^{-1}$. The corresponding mean air pressure in bubbles at the end of pore closure is about $0.083 \mathrm{MPa}$, whereas the atmospheric pressure at this depth level would be $0.063 \mathrm{MPa}$. The influence of the climatic change on the ice-porosity profile is discussed. It resulted in an increased air content in ice at Vostok during the Last Glacial Maximum: $0.096 \mathrm{~cm}^{3} \mathrm{~g}^{-1}$.
\end{abstract}

\section{INTRODUCTION}

The bubbly-ice layer in ice sheets may be considered as an unique natural laboratory where long-term experiments on ice rheology at relatively low stresses are conducted. The porosity and bubble-pressure profiles provide diagnostic results of these compression tests of the heterogeneous airice medium. On the other hand, the density profiles in ice sheets may reflect changes in the initial porosity and the mean bubble pressure at the pore close-off depth (i.e. in the boundary conditions of a bubbly-ice densification model). Indeed, these characteristics control the amount of air trapped in ice (air content) which has been found to be influenced by firn temperature, atmospheric pressure and, probably, wind conditions (Raynaud, 1983; Martinerie and others, 1992, 1994).

A number of experimental density profiles have been obtained from different drilling sites located in Antarctica and Greenland. Earlier attempts to simulate bubble-ice densification and to infer in-situ rheological properties of pure ice from ice porosity (density) measurements have been undertaken by Bader (1965), Salamatin and others (1985) and by Pimienta and Duval (1989). The potential significance of density profiles for the reconstruction of palaeoclimatic conditions at close-off has been discussed by Lipenkov and others (1989). Despite the important and encouraging results obtained by these studies, a better understanding of densification processes is needed to clear up existing uncertainties in data interpretation. In the companion theoretical paper (Salamatin and others, 1997), hereafter referred to as paper I, we have developed a generalized model of bubbleice densification which takes account of the difference between the rheologies of pure and bubbly ices, the change in rheological behavior of ice with stress, the difference between absolute load pressure and pressure in the ice matrix and the contribution of the global deviatoric deformations of the ice-sheet body to the densification process.

In paper I, we also showed that a stationary model could be sufficient to study ice densification and to interpret the experimental data. However, both ice-porosity and bubble-pressure profiles are necessary to obtain a comprehensive solution to the inverse problem of inferring the rheological parameters of ice. With this aim, a special experimental program has been applied to the Vostok ice core. The results include:

Two density (porosity) profiles measured by two independent methods: by hydrostatic weighing and through bubble measurements in thin sections (the latter method avoids the influence of cracks in the brittle zone of the ice core).

A bubble-pressure profile obtained by direct measurements of pressure within individual inclusions.

New air-content data in the upper part of the Vostok ice core. 
Experimental data from seven other sites in Antarctica and Greenland are also used to validate the model and the inferred polynomial rheological law over a wide range of temperatures from $-55^{\circ}$ to $-20^{\circ} \mathrm{C}$. On the other hand, from our interpetation of the Vostok porosity profile (within the bubbly-ice stratum to a depth of $500 \mathrm{~m}$ ), we deduce additional information on the mean values of the air content of Holocene ice and in the ice formed during the Last Glacial Maximum (LGM). The latter value is of special interest because the LGM corresponds to the brittle zone of the Vostok core, where direct air-content measurements are restricted because of ice-core fracturation.

\section{EXPERIMENTAL TECHNIQUES AND DATA}

Most of the Vostok ice cores used in this study were retrieved in 1980-93 by the drilling group from the St. Petersburg Mining Institute (Russia). Experimental data were also obtained on three additional cores recovered in Antarctica at Komsomolskaya Station and at the sites situated at distances of 60 and $105 \mathrm{~km}$ from Mirny. All measurements described in this section were performed on unrelaxed ice, that is to say, either on the fresh ice core soon after drilling or on ice samples stored at a temperature of $-55^{\circ} \pm 1.5^{\circ} \mathrm{C}$, which is low enough to prevent (at least during the first 5 years after drilling) significant changes in the ice properties considered in this study (Lipenkov and Salamatin, 1989).

Published experimental data from Byrd Station, Pionerskaya, Vostok 1 (in Antarctica), as well as from Site 2 (in Greenland) are also used to validate the densification model. The climatic and glaciological conditions at the drilling sites used in this study are given in Table 1.

\section{Density (porosity) measurements}

From the surface to the pore close-off depth, densities of snow and firn were determined on the Vostok ice-core samples by volume and weight measurements (volumetric method). These data are shown in Figure 1 by dots. For the ice below the close-off level, two experimental density (porosity) profiles were obtained independently with two different experimental techniques. The first profile (hereafter referred to as profile I) was measured by hydrostatic weighing. This experimental procedure is essentially the same as that described by Butkovich (1953) and employed by Lang- way (1958) for precise density measurements on the ice core recovered at Site 2 . The experimental density profile I corrected for the effect of cut bubbles (see Martinerie and others, 1990) is shown in Figure 1 by small crosses. The densities in Figure 1 are converted to in-situ conditions in the ice sheet as suggested by Bader (1964). The bounds between the main stages of densification in the Vostok region are marked in Figure 1 (horizontal dotted lines) according to Salamatin and others (1985). The maximal density of ice was estimated experimentally as a mean value of densities measured on 50 ice samples collected from a depth interval $1300-2540 \mathrm{~m}$, which corresponds to bubble-free ice. The resulting value is $0.91664 \mathrm{Mg} \mathrm{m}^{-3}$ at $0^{\circ} \mathrm{C}$ with a standard deviation of \pm $7 \times 10^{-5} \mathrm{Mg} \mathrm{m}^{-3}$. The correction for the effect of enclosed air-hydrate crystals would give a pure ice density of $0.91657 \mathrm{Mg} \mathrm{m}^{-3}$, which is very close to the $0.9165 \mathrm{Mg} \mathrm{m}^{-3}$ value established by Butkovich (1955) for commercial airfree polycrystalline ice. Therefore, both overall absolute error and reproducibility of the measuring procedure used for the Vostok ice core are found to be within $\pm 10^{4}$. The largest uncertainties on density results are linked to the presence of fractures in the brittle zone between 250 and $750 \mathrm{~m}$ in the Vostok ice core (see Fig. 1). The mean value of the fissure effect on the density data obtained with the hydrostatic method is estimated to be $1-2 \times 10^{-4} \mathrm{Mg} \mathrm{m}^{-3}$ for the Vostok ice core. The most badly fractured samples may give an underestimate of up to $5 \times 10^{-4} \mathrm{Mg} \mathrm{m}^{-3}$ which leads to a significant overestimation of the porosity. These samples (indicated in Figure 1 by circles) have not been used in our study.

The porosity profile II (shown in Figure 1 by small open circles) was established from the data on the bubble size vs number distribution obtained by measuring the bubbles on thin sections using a binocular microscope. The air-volume concentration (ice porosity) was then calculated on the basis of a log-normal distribution (Barkov and Lipenkov, 1984). The accuracy of this method is considered to be less than half that of the first method but the obvious advantage of this technique is that the results are free from the influence of fractures.

\section{Bubble-pressure measurements}

Direct measurements of gas pressure within individual air inclusions were performed using the experimental proced-

Table 1. Ice-formation conditions for the eight drilling sites in Antarctica and Greenland

\begin{tabular}{|c|c|c|c|c|c|c|c|c|c|c|c|}
\hline \multirow[t]{2}{*}{ Drilling site } & \multirow[t]{2}{*}{ Location } & $T_{\mathrm{c}}$ & $b$ & $P_{\mathrm{atm}}$ & $h_{\mathrm{c}}$ & $P_{\mathrm{lc}}$ & $c_{\mathrm{c}}$ & $V$ & $P_{\text {be }}$ & $\rho_{\mathrm{i}}$ & $\Delta$ \\
\hline & & ${ }^{\circ} \mathrm{C}$ & $\mathrm{g} \mathrm{cm}^{-3}$ year ${ }^{-1}$ & $\mathrm{MPa}$ & $\mathrm{m}$ & $\mathrm{MPa}$ & & $\mathrm{cm}^{3} \mathrm{~g}^{-1}$ & $\mathrm{MPa}$ & $\mathrm{Mg} \mathrm{m}^{-3}$ & $\mathrm{~m}$ ice eq. \\
\hline $60 \mathrm{~km}$ & East Antarctica & -20 & 47 & 0.088 & 55 & 0.452 & 0.105 & 0.126 & 0.093 & 0.919 & 560 \\
\hline $105 \mathrm{~km}$ & East Antarctica & -24 & 36 & 0.085 & 65 & 0.528 & 0.098 & 0.119 & 0.093 & 0.920 & 1330 \\
\hline Site $2^{1}$ & Greenland & -25 & 39 & 0.078 & 71.5 & 0.545 & 0.091 & $0.110^{*}$ & $0.093^{*}$ & 0.920 & 2000 \\
\hline Byrd $^{2}$ & West Antarctica & -28 & 16 & 0.081 & 64 & 0.499 & 0.093 & 0.112 & 0.091 & 0.920 & 2150 \\
\hline Pionerskaya $^{3}$ & East Antarctica & -38.5 & 12.5 & 0.070 & 90 & 0.680 & 0.083 & 0.096 & 0.085 & 0.922 & 2000 \\
\hline Vostok $\mathrm{I}^{+}$ & East Antarctica & -47 & 7.6 & 0.065 & 110 & 0.803 & 0.085 & $0.100^{*}$ & $0.083^{*}$ & 0.923 & 3250 \\
\hline Komsomolskaya & Central Antarctica & -53.5 & 6.5 & 0.063 & 120 & 0.847 & 0.074 & $0.079^{*}$ & $0.074^{*}$ & 0.923 & 3515 \\
\hline Vostok & Central Antarctica & -56 & 2.2 & 0.063 & 105 & 0.746 & 0.073 & $\begin{array}{l}0.086 \\
0.088^{*}\end{array}$ & $\begin{array}{l}0.081 \\
0.083^{*}\end{array}$ & 0.920 & 3690 \\
\hline
\end{tabular}

\footnotetext{
${ }^{1}$ Langway, 1958, 1967; ${ }^{2}$ Gow, 1968a, b; ${ }^{3}$ Smirnov, 1983; Petrov and others, $1989 ;{ }^{4}$ Salamatin and others, 1985.

* These values were inferred through identification of the model with experimental data on bubbly-ice densification.
} 


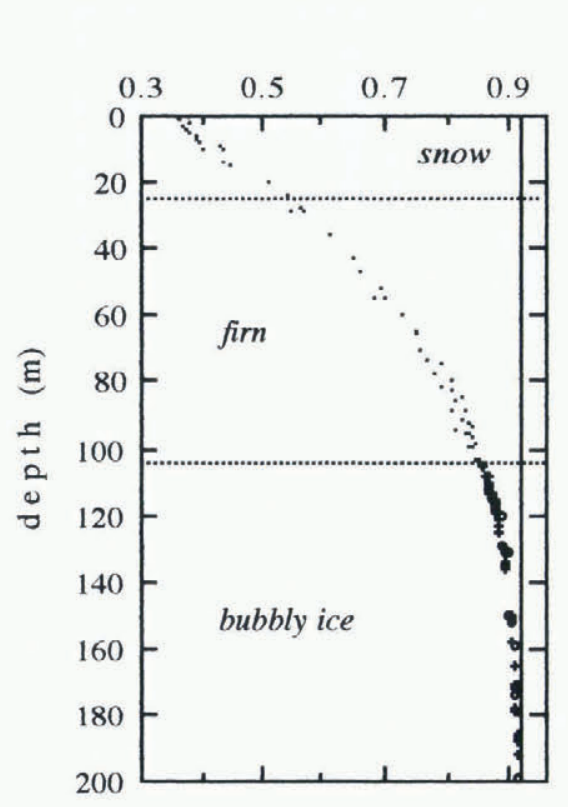

Experimental technique: · volumetric method

- hydrostatic weighing

- bubble measurements density $\left(\mathrm{Mg} \mathrm{m}^{-3}\right)$

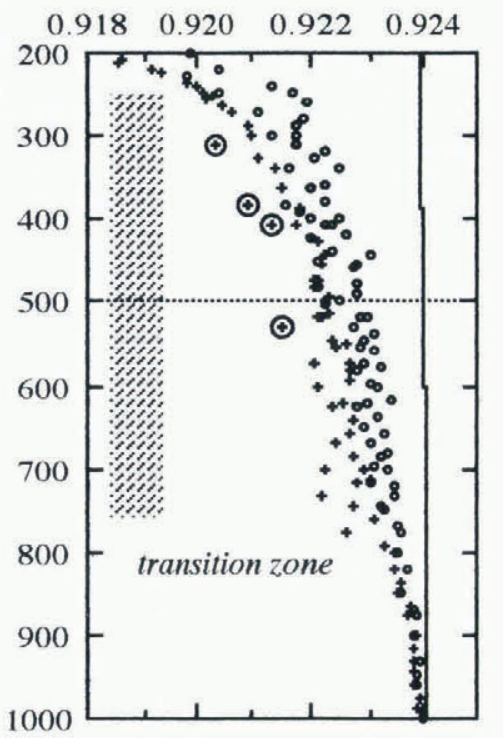

Quality of ice core:

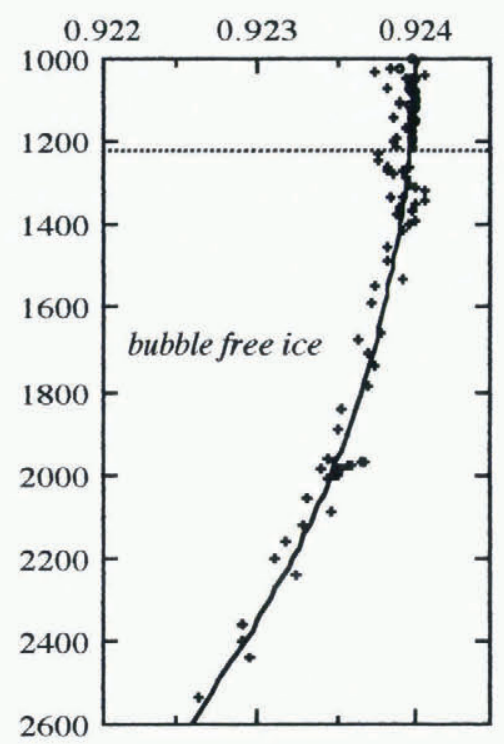

兴 brittle-fractured ice

○ badly fractured ice specimens

Fig. 1. Vostok ice-core density profiles obtained using different experimental techniques. From the surface to the close-off depthdensity, measurements were performed using a volumetric method, and below the close-off depth, by hydrostatic weighing. An independent density profile below the close-off was obtained from air-bubble number-size distributions of the air bubbles which were measured on thin sections at different depth levels. The solid line represents a maximal density of glacier ice when all air bubbles are transformed into air-hydrate crystals. Horizontal dotted lines represent the bounds between the main stages of densification of ice sediments.

ure suggested by Scholander and Nutt (1960) and further developed by Gow and Williamson (1975). The measuring technique is based on a pressure chamber with an attached binocular microscope for observation of the bubble. The chamber containing the ice sample is filled with ethylene glycol; this results in an eutectic melting of ice at a temperature of about $-8^{\circ} \mathrm{C}$. When the bubbles open due to ice melting, the meniscus either collapses or expands, depending on the relation between pressure in the chamber and that in the bubble. Pressure in the chamber, measured by high-precision pressure gauges and regulated through an hydraulic pump, can be matched to the bubble pressure by adjusting the air meniscus to be flat at the moment of bubble opening; pressure in the bubble at this time is equal to the pressure recorded in the chamber. The pressure of about 100 air inclusions was measured for each depth level, allowing us to calculate the mean pressure as well as its dispersion at a given depth.

The experimental data for the Vostok ice core are presented in Figure 2a as a difference between bubble pressure and pressure in the ice matrix (bubble-pressure lag) vs depth. These seem to be the first direct measurements performed on an unrelaxed ice core shortly after its recovery. Actually, Langway (1958) evaluated bubble pressure in the ice core at Site 2 (Greenland) from air-content and density (porosity) measurements, while direct studies by Gow and Williamson (1975) on diffferent ice cores from Antarctica (Byrd and old Byrd Stations) and Greenland (Site 2 and Camp Century) were all conducted after at least 3 years of ice relaxation.The bubble-pressure lag is found to be significant for two depth intervals: first, from the close-off level to about $250 \mathrm{~m}$ (i.c. within the relaxation phase of the ice densification according to paper I), and secondly, below $600 \mathrm{~m}$, where the highly pressurized bubbles may relax even during

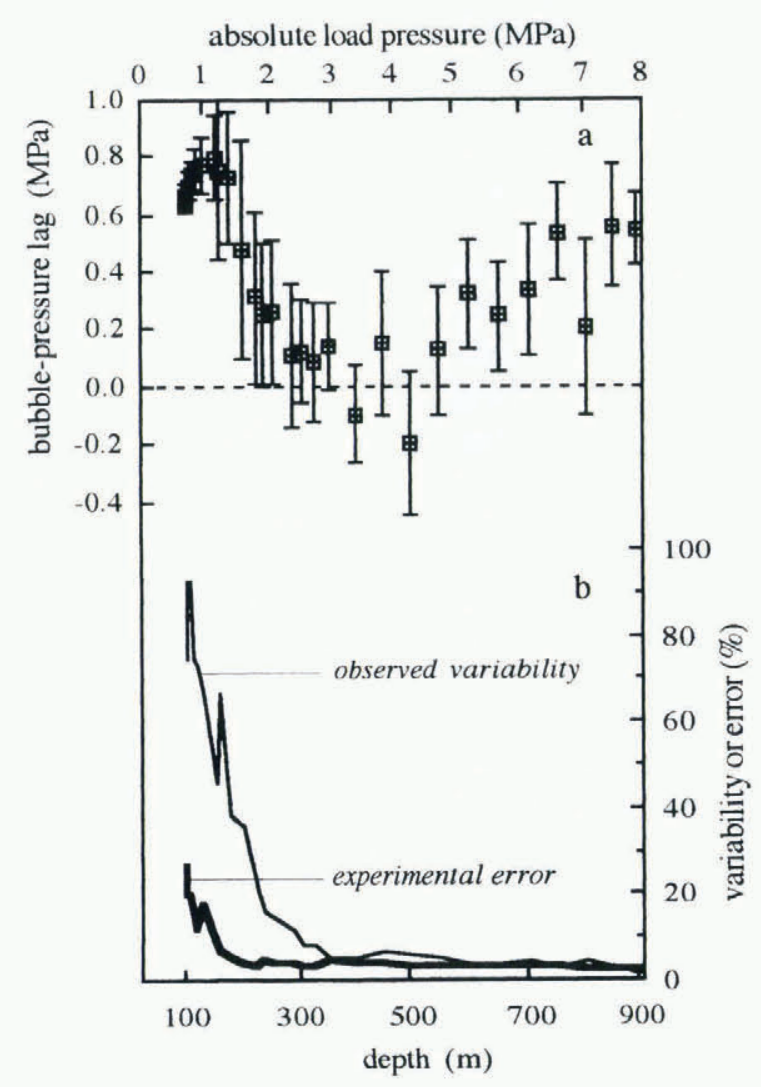

Fig. 2. Bubble pressure in the Vostok ice core. (a) Bubble-pressure lag vs absolute load pressure (and depth in meters of ice equivalent). Vertical bars indicate a variability of the pressure measured in the individual inclusions at the same depth level. (b) Comparison of bubble-pressure variability and experimental error on pressure measurements along the Vostok ice core. 
the time of the experiment being carried out at a relatively warm temperature. At the same time, the bubble pressure in a depth interval of 250-600 $\mathrm{m}$ (asymptotic phase of the densification in paper I) is very close to the pressure in the ice matrix, which supports the fact that this ice has undergone no significant relaxation after drilling. Moreover, a slight overestimation of the mean bubble pressure can be suggested if we take into account several points between 250 and $600 \mathrm{~m}$ with very low or even negative values of bubblepressure lag.

The total bubble-pressure variability observed in the experiment may originate from experimental error as well as from a natural variability of the bubble pressure caused by the relatively wide depth interval $(10-15 \mathrm{~m}$ at Vostok Station) over which the pore-closure process takes place. The comparison between the observed variability and the estimated experimental error along the Vostok ice core is shown in Figure 2b. The natural variability of bubble pressure decreases with depth and becomes negligible (does not exceed $\pm 10 \%$ ) below $300 \mathrm{~m}$, i.e. at the asymptotic phase of the densification process. This is consistent with theoretical predictions and supports the reliability of both the experimental data and our estimates of their accuracy. Finally, we may conclude that the obtained bubble-pressure profile is valid down to a depth of $600 \mathrm{~m}$ within uncertainties indicated by the error bars.

\section{Air content in the Vostok ice core}

The published air-content profile in the Vostok ice core down to a depth of $2546 \mathrm{~m}$ (Lipenkov and others, 1993; Martinerie and others, 1994) includes only a few measurements in its upper part. These measurements were considered as imprecise due to ice-core fracture. The deeper part of the record (below the end of the brittle zone, from a depth of about $750-800 \mathrm{~m}$ ) is of high resolution and is well documented. Additional measurements were performed on unfractured samples from mechanically drilled ice cores, using a new barometric method (Lipenkov and others, 1995). Both old and new experimental profiles corrected for the cutbubble effect are shown in Figure 3 down to a depth of $280 \mathrm{~m}$. The air content is expressed here as a volume $\left(\mathrm{cm}^{3} \mathrm{STP}\right)$ of dry air in $1 \mathrm{~g}$ of ice (STP: $T_{\mathrm{s}}=273 \mathrm{~K}$, $\left.P_{\mathrm{s}}=0.1013 \mathrm{MPa}\right)$. In the lower part of the bubbly-ice stratum from 280 to $500 \mathrm{~m}$ there are several single measurements performed on fractured ice but they are not considered at this stage. Comparison of the two data sets in Figure 3 does not reveal any systematic difference between them. The new data show significant variations of the air content within the Holocene-age ice in the Vostok ice core, although comparable with the typical fluctuations of about $\pm 10 \%$ in the deeper part of the air-content record around a mean value of $0.09 \mathrm{~cm} \mathrm{~g}^{-3}$. Two levels of air content in the Holocene can be distinguished here. The lower one (hereafter we call it present-day air-content level: $0.0818 \pm 0.0015 \mathrm{~cm}^{3} \mathrm{~g}^{-1}$ ) was determined from 19 ice samples that continuously covered the ice-core increment $122.19-122.75 \mathrm{~m}$. Such continuous testing is used to avoid a possible stratigraphic effect on the mean value. The higher level (indicated in Figure 3 as a Holocene level) with an air content of $0.0862 \pm 0.025 \mathrm{~cm}^{3} \mathrm{~g}^{-1}$ was obtained in the same way on 22 samples cut from the ice-core depth range $182.39-183.00 \mathrm{~m}$. When comparing the two air-content levels observed in the recent ice down to $280 \mathrm{~m}$ depth with a full profile of the $2546 \mathrm{~m}$ long ice core

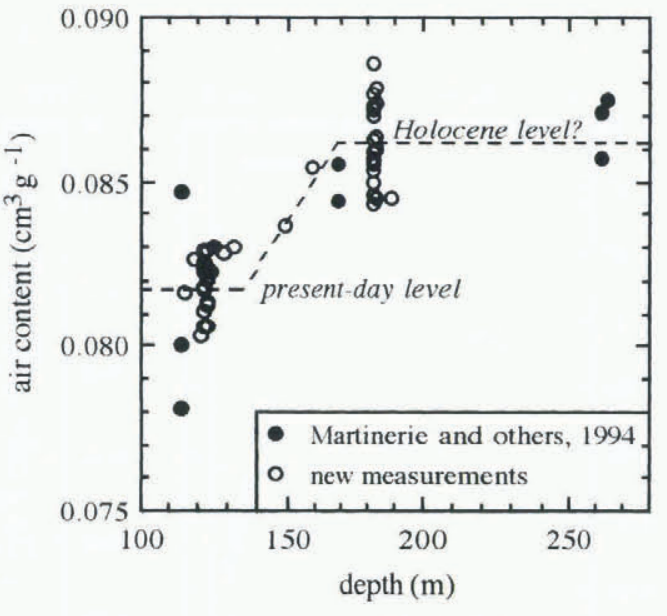

Fig. 3. Air content vs depth for Holocene ice at Vostok Station. Present-daylevel of air content $\left(0.0818 \mathrm{~cm}^{3} \mathrm{~g}^{-1}\right)$ and Holocene level $\left(0.0862 \mathrm{~cm}^{3} \mathrm{~g}^{-}\right)$are determined as the mean values of air content in the two ice-core increments (122.19-122.75 m and 182.39-183.00 $\mathrm{m}$, respectively) which were continuously tested in every $2.5-3.0 \mathrm{~cm}$ layer.

(see Martinerie and others, 1994), one can conclude that the present-day level depicted in Figure 3 corresponds to one of the lowest air-content values ever measured in Vostok ice. Thus, it seems likely that this event, occurring now just below pore close-off, may be considered as a typical example of the rapid variations frequently observed in the high-resolution air-content record from the Vostok ice core. These events are thought to be caused by relatively shortterm variations in wind and weather conditions which affect the initial properties of surface snow, and thus the resultant porous volume in ice at the air-isolation level (Martinerie and others, 1994). However, this low air content in the vicinity of close-off may also be partly attributed to a possible underestimation of the cut-bubble effect, since at these depths (down to $170 \mathrm{~m}$ ) bubbles have essentially elongated shapes and the process of their disintegration is not completed. The higher level of the air content designated in Figure 3 as a Holocene level is probably the best estimate for the mean air content in Holocene ice from available experimental data.

\section{MODEL PRESENTATION AND CONCRETIZATION}

Theoretical paper I gives a general mathematical model for simulating the depth profiles of air-volume concentration or ice porosity $(c)$ and bubble pressure $\left(P_{\mathrm{b}}\right)$ below the close-off depth $\left(h_{c}\right)$ in an ice sheet, provided that rheological properties of ice and close-off conditions are determined. Numerical calculations are based on finite-difference and iterative methods. In this section, we introduce the main parameters of the model and present a brief description of its basic relations which must be known to understand the model validation as well as for further interpretation of the experimental data which is considered as the primary goal of this study.

\section{The form of the constitutive relation}

In the model, the rheological relationship between the effective stresses $\tau=(0.5: \tau)^{\frac{1}{2}}$ and strain rates $\dot{e}=(0.5 \dot{\mathbf{e}}: \dot{\mathbf{e}})^{\frac{1}{2}}$ in pure polycrystalline ice ( $\tau$ and $\dot{\mathbf{e}}$ ) are the stress and strain- 
rate tensors) is written in the polynomial form as proposed by Budd (1969) and Shumskiy (1969):

$$
2 \dot{e}=\tau / M_{1}+\tau^{\alpha} / M_{2} \text {. }
$$

Here, $\alpha$ is the exponent (creep index) and $M_{1}$ and $M_{2}$ are the rheological coefficients, which are depndent on temperature $T$ (in $\mathrm{K}$ ),

$$
M_{j}=\mu_{j} \exp \left[\frac{Q_{j}}{R_{\mathrm{s}} T_{\mathrm{s}}}\left(\frac{T_{\mathrm{s}}-T}{T}\right)\right] \quad j=1,2
$$

where $\mu_{1}$ and $\mu_{2}$ are constant factors, $Q_{1}$ and $Q_{2}$ are the apparent activation energies, $R_{\mathrm{s}}$ is the gas constant: $R_{\mathrm{s}}=8.314 \mathrm{~J}(\operatorname{mole} \cdot \mathrm{K})^{-1}$ and $T_{\mathrm{s}}$ is the standard temperature: $T_{\mathrm{s}}=273.15 \mathrm{~K}$.

Equations (3.1) and (3.2) contain five parameters $\alpha, \mu_{1}$, $\mu_{2}, Q_{1}$ and $Q_{2}$ which identify ice rheology. This set is considered to be sufficient to provide a good approximation of any experimental flow law in limited ranges of stresses and temperatures.

\section{Space- and time-scales of bubbly-ice densification}

Let us further distinguish as $P_{1}$ the load pressure in the ice and as $P_{\text {atm }}$ and $b$ the present-day conditions: the mean Holocene atmospheric pressure at pore close-off and ice-accumulation rate, respectively. The maximal pressure drop between air in bubbles and ice is of the order of $P_{\mathrm{lc}}-P_{\mathrm{atm}}$ (subscript " $c$ " hereafter designates the values related to the close-off depth) and, in accordance with paper I, the characteristic depth $\left(h^{0}\right)$ and time $\left(t^{0}\right)$ scales of the bubbly-ice densification process are determined as

$$
\left.h^{0} \approx\left(P_{\mathrm{lc}}-P_{\mathrm{atm}}\right) / g \rho_{\mathrm{i}}\right), \quad t^{0} \approx h^{0} / b
$$

where $g$ is the gravity acceleration and $\rho_{\mathrm{i}}$ is the density of pure ice (the mean value in the temperature range prevailing in the bubbly-ice stratum of the ice sheet). Actually, $h^{0}$ is the close-off depth expressed in ice equivalent. For example, at Vostok Station for the present-day conditions (see Table 1),

$$
h^{0} \approx 76 \mathrm{~m}, \quad t^{0} \approx 3.2 \text { kyear } .
$$

Consequently, even for central Antarctica with extremely low snow accumulation, the high-rate densification phase, which (see paper I) does not exceed $3 h^{0}$ with respect to depth or $3 t^{0}$ with respect to age, covers only a $150 \mathrm{~m}$ depth interval (or 6.5 kyear period in time) below pore close-off. Therefore, this phase of the densification process always ends within the Holocene-age ice thickness which has been formed at relatively stable climatic conditions. Deeper in ice sheets, the so-called asymptotic phase of densification takes place and the bubble-pressure profile no longer depends on the past climatic changes at bubble closure. Thus, the stationary mathematical description of the densification process with invariable mean-Holocene conditions at the close-off depth is sufficient for computational predictions.

\section{Dimensionless parameters of the model}

The normalized bubble pressure $\bar{P}_{\mathrm{b}}$ can be evaluated as a function of the model parameters in the following dimensionless form:

$$
\bar{P}_{\mathrm{b}}=\varphi\left(\bar{h} ; \alpha, K_{1}, K_{2}, \bar{\gamma}_{\mathrm{c}}, \bar{P}_{\mathrm{atm}}, \bar{\epsilon}_{1}, \bar{\epsilon}_{\mathrm{a}}, \kappa\right)
$$

where

$$
\begin{aligned}
\bar{P}_{\mathrm{b}} & =\frac{P_{\mathrm{b}}}{P_{\mathrm{lc}}-P_{\mathrm{atm}}}, \quad \bar{h}=\frac{h^{\prime}}{h^{0}}, \quad \bar{P}_{\mathrm{atm}}=\frac{P_{\mathrm{atm}}}{P_{\mathrm{lc}}-P_{\mathrm{atm}}}, \\
\bar{\epsilon}_{1} & =\epsilon_{1} t^{0}, \quad \bar{\epsilon}_{\mathrm{a}}=\epsilon_{\mathrm{a}} t^{0}, \quad K_{1}=\frac{4 g \rho_{\mathrm{i}} b M_{1}}{3\left(P_{\mathrm{lc}}-P_{\mathrm{atm}}\right)^{2}} \\
K_{2} & =\frac{g \rho_{\mathrm{i}} b M_{2}}{\left(P_{\mathrm{lc}}-P_{\mathrm{atm}}\right)^{\alpha+1}}\left(\frac{2}{\sqrt{3}}\right)^{\alpha+1}, \quad \bar{\gamma}_{\mathrm{c}}=\frac{c_{\mathrm{c}} \bar{P}_{\mathrm{bc}}}{1-c_{\mathrm{c}}} .
\end{aligned}
$$

Some new denotations are used in Equations (3.4) and (3.5): according to paper I, $\kappa$ is the tuning parameter of the bubbly-ice rheological model (Salamatin and Duval, 1997) assumed hereafter equal to $0.7 ; \epsilon_{1}$ is the thinning rate in the vertical direction and $\epsilon_{\mathrm{a}}$ is the apparent strain rate in the upper part of the ice sheet induced by overall glacier flow; $h^{\prime}$ is the depth measured in the equivalent of pure ice related to the real depth $h$ by the equation

$$
h^{\prime}=h^{0}+\int_{h_{\mathrm{c}}}^{h}(1-c) \mathrm{d} h, \quad h>h_{\mathrm{c}} .
$$

Hence, the reduced dimensionless depth $\bar{h}$ is the normalized load pressure

$$
\bar{h}=\left(P_{1}-P_{\text {atm }}\right) /\left(P_{\mathrm{lc}}-P_{\text {atm }}\right) .
$$

The air-volume concentration is straightforwardly expressed as a function of $\bar{P}_{\mathrm{b}}$ :

$$
c=\bar{\gamma}_{\mathrm{c}} /\left(\bar{\gamma}_{\mathrm{c}}+\bar{P}_{\mathrm{b}}\right) \text {. }
$$

The dimensionless complex $\bar{\gamma}_{c}$ can be considered as a characteristic value of the bubbly-ice porosity and is proportional to the air content $V$ in the ice

$$
V=\frac{\left(P_{\mathrm{lc}}-P_{\mathrm{atm}}\right) T_{\mathrm{s}}}{\rho_{i} P_{\mathrm{s}} T_{\mathrm{c}}} \bar{\gamma}_{\mathrm{c}}
$$

where $P_{\mathrm{s}}$ is the standard pressure: $P_{\mathrm{s}}=0.1013 \mathrm{MPa}$.

The relationship (3.4) is the solution of a non-linear integral-differential equation derived in paper I. Finitedifference and iterative methods are used to calculate $P_{\mathrm{b}}$ and $c$ in Equations $(3.4)-(3.7)$ vs depth $h$ (or $\bar{h}$ ). "Lincar" and "non-linear" viscosities $M_{1}$ and $M_{2}$ in Equations (3.1) and (3.2) (criteria $K_{1}, K_{2}$ in Equations (3.5)) are estimated at the mean close-off temperature $T_{\mathrm{c}}$.

\section{MODEL APPLICATION TO THE VOSTOK ICE- CORE DATA}

The ice-densification model can be used to calculate directly porosity and bubble-pressure profiles for given parameters of the densification process listed in Equations (3.4) and (3.5). We also developed an inverse method in order to infer the air content $V$ and the rheological parameters $M_{1}$ and $M_{2}$ of pure ice (i.e. $\bar{\gamma}_{c}$ and $K_{1}, K_{2}$ ) from porosity and (or) bubble-pressure experimental profiles. This section describes our approach and its application to the Vostok icecore data.

\section{The inverse problem}

It has been shown in paper I that porosity and bubble-pressure profiles in the bubbly-ice thickness are selectively sensitive to the main parameters of the model: bubble pressure can be used to distinguish between $K_{1}$ and $K_{2}$ but does not reveal changes $\bar{\gamma}_{c}$, while the porosity profile, on the contrary, is equally influenced by $K_{1}$ and $K_{2}$ but is very sensitive to $\bar{\gamma}_{c}$. Hence, we need both data sets to determine fully all these values. 
Let $c^{(k)}$ and $P_{\mathrm{b}}{ }^{(j)}$ be the porosity and mean pressure in the air bubbles measured at the depth levels $h_{k}, k=1,2, \ldots$, $m$ and $h_{j}, j=1,2, \ldots, n$, respectively. The two comparable normalized mean-square (standard) deviations can be introduced as

and

$$
\bar{s}_{\mathrm{c}}=s_{\mathrm{c}} / c_{\mathrm{c}}=\frac{1}{c_{\mathrm{c}}}\left[\sum_{k=1}^{m}\left(c^{(k)}-c\left(h_{k}\right)\right)^{2} / m\right]^{\frac{1}{2}}
$$

$$
\bar{s}_{\mathrm{p}}=s_{\mathrm{p}} /\left\langle P_{1}\right\rangle=\frac{1}{\left\langle P_{1}\right\rangle}\left[\sum_{j=1}^{n}\left(P_{\mathrm{b}}{ }^{(j)}-P_{\mathrm{b}}\left(h_{j}\right)\right)^{2} / n\right]^{\frac{1}{2}}
$$

where $\left\langle P_{1}\right\rangle=0.5\left(P_{\mathrm{lc}}+P_{1}\left(h_{n}\right)\right)$ is the mean load pressure; $c\left(h_{k}\right)$ and $P_{\mathrm{b}}\left(h_{j}\right)$ are the corresponding simulated values determined by Equations (3.4)-(3.7).

So, we formulate the inverse problem of inferring parameters $K_{1}, K_{2}$ and $\bar{\gamma}_{\mathrm{c}}$ as the best-fit procedure of minimizing the target function

$$
\bar{s}^{2}=w \bar{s}_{\mathrm{c}}^{2}+(1-w)\left(\bar{s}_{\mathrm{p}}\right)^{2},
$$

which is the weighted average of $\bar{s}_{\mathrm{c}}$ and $\bar{s}_{\mathrm{p}}$ with the weight $0 \leq w \leq 1$ usually taken as $w=0.5$.

The gradient method of steepest descent is applied to perform the computations. A number of numerical tests have been carried out using Vostok ice-core data. The main results of the tests are presented below.

\section{Preliminary tests}

It should be noted that the process of bubbly-ice densification occurs at relatively low stresses: $\tau<\left(P_{\mathrm{lc}}-P_{\mathrm{atm}}\right)$, which corresponds to the transition of the rheological law in Equation (3.1) of pure ice from asymptotic power creep to linearviscous flow (see paper I). Within this range, the original relationship between $\dot{e}$ and $\tau$ can be equally well approximated by Equation (3.1) at different $\alpha$, provided that the parameters $M_{1}$ and $M_{2}$ are properly adjusted. This has been confirmed by preliminary tests: practically the same rheological curve within the transition zone is obtained for various values of the exponent in the interval $2 \leq \alpha \leq 5$. Finally, the exponent has been fixed in accordance with Budd (1969) and Shumskiy (1969) at $\alpha=3.5$ to represent the high-stress branch of the ice-flow law.

Since $\bar{\epsilon}_{1}$ and $\bar{\epsilon}_{\mathrm{a}}$ in central Antarctica at Vostok Station are expected to be small and do not significantly influence the model prediction of $P_{\mathrm{b}}$ and $c$ (see paper $\mathrm{I}$ ), a simple two-dimensional flow of the glacier along a flow tube of constant width is assumed below to estimate $\bar{\epsilon}_{1}$ and $\bar{\epsilon}_{\mathrm{a}}$ in Equations (3.4) and (3.5). Hence,

$$
\bar{\epsilon}_{1}=\bar{\epsilon}_{\mathrm{a}}=b t^{0} / \Delta=\left(P_{\mathrm{lc}}-P_{\mathrm{atm}}\right) /\left(g \rho_{\mathrm{i}} \Delta\right)
$$

where $\Delta$ is the thickness of the ice sheet in the equivalent of pure ice.

Initial data on the ice-formation conditions and densification process at Vostok Station are given in Table 1.

It is clear that only $M_{1}, M_{2}$ (i.e. $K_{1}, K_{2}$ ) and, if necessary, $P_{\mathrm{bc}}\left(\bar{\gamma}_{\mathrm{c}}\right.$ or $\left.\bar{P}_{\mathrm{bc}}\right)$ need to be found to constrain the model in Equations (3.4) - (3.7). To do this, the best fit to experimental data is determined within fixed depth limits: $1<\bar{h}<3.5$, that include a complete high-rate phase of the densification as well as the beginning of the asymptotic phase. At Vostok Station, this corresponds to a depth interval $105<h<300 \mathrm{~m}$, which covers the entire Holocene period with respect to entrapped air age (Barnola and others, 1991). The recent change of the air-content level $(5 \%$ increase) observed within Holocene ice at Vostok at a depth of about $150 \mathrm{~m}$ (see Fig. 3) does not imply any significant disturbances, neither in the bubble-pressure profile, because the latter is not sensitive to $\gamma_{\mathrm{c}}$, nor in the porosity, which is determined mainly by the air content in ice below $170 \mathrm{~m}$ (when $c_{\mathrm{c}}$ is fixed as the measured present-day value). This allows us to compute the bubbly-ice densification as a stationary process at a mean effective value of $\gamma_{c}$, which is expected to be close to the higher (Holocene) level of air content depicted in Figure 3.

\section{Rheological parameters and air content in Holo- cene ice at Vostok inferred from experimental por- osity and bubble-pressure profiles}

To infer the rheological parameters of pure icc and to estimate the mean bubble pressure at pore-isolation level in the Vostok region, we first try to identify the model on full initial datasets consisting of two porosity profiles (I and II) and the bubble-pressure profile obtained through direct presssure measurements.

Minimization of the $\bar{s}$ function $(4.1$ at $w=0.5$ gives $K_{1} \approx 0.61, K_{2} \approx 0.41$ for both porosity profiles but results in different estimations of the characteristic porosity: $\bar{\gamma}_{\mathrm{c}}=0.01\left(P_{\mathrm{bc}} \approx 0.086 \mathrm{MPa}\right)$ in case $\mathrm{I}$ and $\bar{\gamma}_{\mathrm{c}}=0.0096$ $\left(P_{\mathrm{bc}} \approx 0.084 \mathrm{MPa}\right)$ in case II. As described in section 2 , the difference between profiles I and II is due to ice fracture: the ice porosity determined by hydrostatic weighing (profile I) is systematically higher than that calculated from direct measurements of the size and number of air bubbles in the ice (profile II). Thus, the first profile represents the upper estimation of porosity, while the second, being less precise, seems to slightly underestimate this quantity. This is the reason for the apparent difference between the deduced values of $\bar{\gamma}_{\mathrm{c}}$ and $P_{\mathrm{bc}}$. Furthermore, we consider $P_{\mathrm{bc}}=0.085 \mathrm{MPa}\left(\bar{\gamma}_{\mathrm{c}}=0.0098\right)$ as an improved upper bound of the bubble pressure prevailing at the close-off depth at Vostok Station during the Holocene period. The best fits for porosity and bubble-pressure profiles obtained through conditional minimizing of the standard deviation in Equation (4.1) as a function of $K_{1}$ and $K_{2}$ at fixed $\bar{\gamma}_{\mathrm{c}}=0.0098\left(P_{\mathrm{bc}}=0.085 \mathrm{MPa}\right)$ are depicted by curves $1 \mathrm{in}$ Figure $4 \mathrm{a}$ and $\mathrm{b}$, respectively.

It should also be emphasized that, as long as the experimental pressure profile remains unchanged, the inferrable rheological parameters appear to be very stable with respect to changes of $\bar{\gamma}_{\mathrm{c}}$ (i.e. $P_{\mathrm{bc}}$ ) or to substitutions of porosity profiles I and II. The variations do not exceed $\pm 1 \%$ for $K_{1}$ and $\pm 5 \%$ for $K_{2}$, when $\bar{\gamma}_{\mathrm{c}}$ is forced to skip from $\bar{\gamma}_{\mathrm{c}}=$ $0.01\left(P_{\mathrm{bc}} \approx 0.086 \mathrm{MPa}\right)$ to $\bar{\gamma}_{\mathrm{c}}=0.0094\left(P_{\mathrm{bc}} \approx 0.082 \mathrm{MPa}\right)$. The relative mean-square deviation is $\bar{s} \approx 2.8 \times 10^{-2}$ and $3.1 \times 10^{-2}$ (that corresponds, respectively, to the standard deviation of porosity $s_{\mathrm{c}}=2.1 \times 10^{-3}$ and $2.7 \times 10^{-3}$ for profiles I and II and to the deviation of pressure $s_{\mathrm{p}}=$ $\left.3.8 \times 10^{-2} \mathrm{MPa}\right)$.

The air content in the young Vostok ice from the close-off depth to about $150 \mathrm{~m}$ is found to be rather low (see Fig. 3). This may be a possible explanation for the fact that all the points of the experimental porosity profile I in this depth interval lie below the simulated curve (Fig. 4a). Another candidate to account for the above-mentioned discrepancy in Figure $4 \mathrm{a}$ is the process of bubble disintegration, which is 
normalized depth
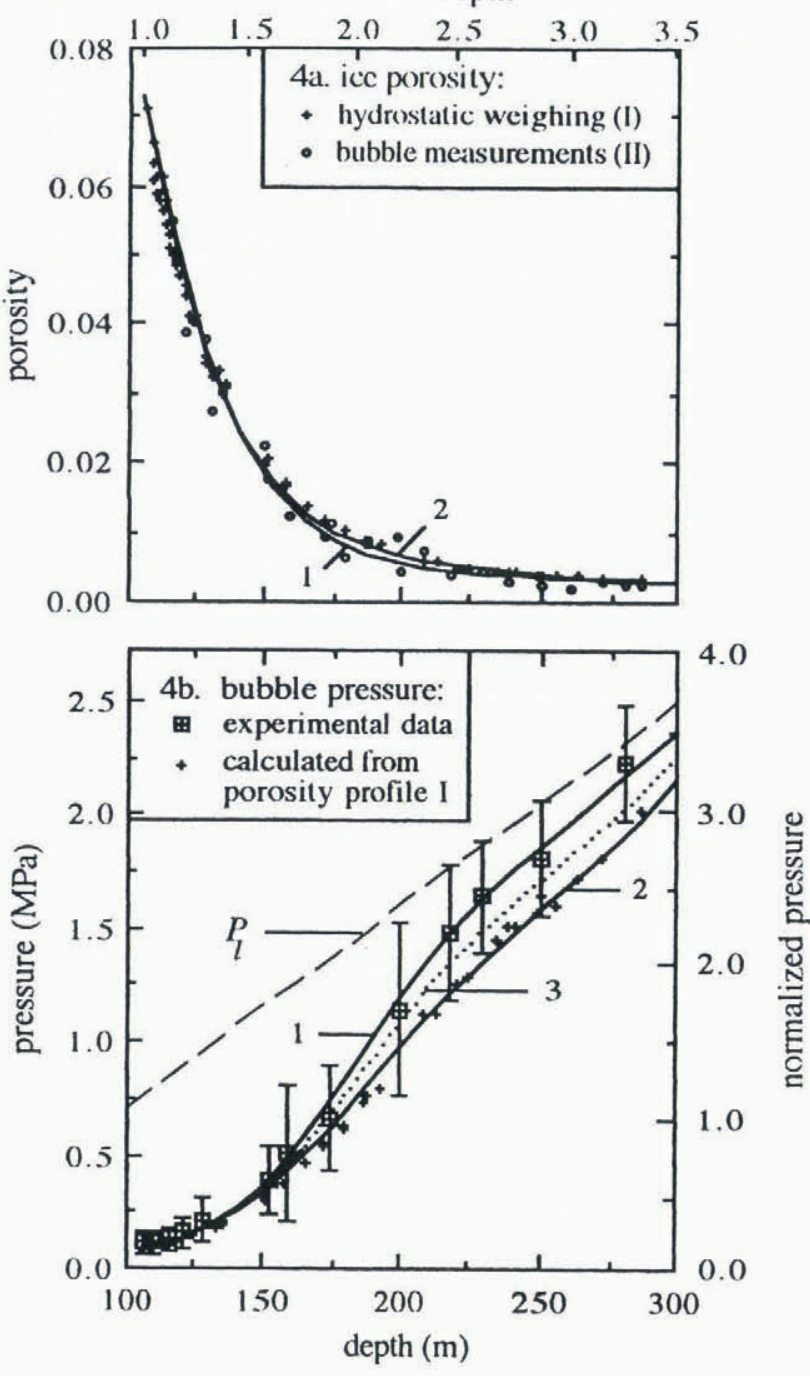

Fig. 4. Best-fit ice porosity (a) and bubble-pressure (b) curves simulated through model fitting to the Vostok ice-core data. Experimental data are shown with symbols as indicated in the figures. Curves 1 in both figures correspond to a best fit between the model and the full original data set consisting of the experimenlal bubble-pressure profile and both of the porosity profiles: I and II. Curves 2 are related to the porosity profile I and to the bubble pressure calculated from porosity profile I. The dotted line 3 in (b) represents the bubble-pressure profile giving the middle values of the pressure as compared to curves 1 and 2. The dashed line in $(b)$ is the absolute-load pressure.

observed at Vostok down to a depth of $170 \mathrm{~m}$ and is not taken into account by the model.

The next step is to estimate the possible influence of the errors in the bubble-pressure measurements on the icerheology predictions. As the depth increases, the mean pressure in air bubbles becomes very close to the absolute load pressure (dashed line in Figure 4b) and, thus, is thought to be not less than the real mean bubble pressure. On the other hand, the lower bound of the bubble pressure is determined by the lower marks of the error bars, which indicate the variability of the gas pressure measured in individual bubbles at the same depth level. Note also that overestimation of the porosity $c$ in Equation (3.7) would lead to an underestimation of the magnitudes of $\bar{P}_{\mathrm{b}}$ and, what is most important, the larger $\bar{\gamma}_{\mathrm{c}}$ is, the larger the values of $\bar{P}_{\mathrm{b}}$ are. Therefore, in order to determine a lower estimate for $\bar{\gamma}_{\mathrm{c}}$ and, hence for $P_{\mathrm{bc}}$ we should relate, in accordance with Equation (3.7), the experimental porosity profile I (i.e. overestimated porosity) to the lower marks of the error bars in the bubble-pressure measurements. This yields $\gamma_{c}=0.0094$ and therefore $P_{\mathrm{bc}} \approx 0.082 \mathrm{MPa}$. We believe that this value represents the lower bound of the bubble pressure prevailing at the close-off depth in the Vostok region during the Holocene period. The bubble-pressure profile recalculated from porosity-data set $\mathrm{I}$ is shown by small crosses in Figure 4b, while curves 2 in Figure $4 \mathrm{a}$ and b represent the corresponding best fits $\left(\bar{s}=2.1 \times 10^{-2}, s_{\mathrm{c}}=1.7 \times 10^{-3}, s_{\mathrm{p}}=2.9 \times\right.$ $10^{2} \mathrm{MPa}$ ) of the model in Equations (3.1)-(3.7) at $w=0.5$ in Equation (4.1). The inferred values of the rheological parameters are $K_{1} \approx 2.9$ and $K_{2} \approx 0.053$ and globally, at this stage, we have

$$
\begin{aligned}
0.61 & \leq K_{1} \leq 2.9, \quad 0.053 \leq K_{2} \leq 0.41 \\
0.0094 & \leq \bar{\gamma}_{c} \leq 0.01 \quad\left(0.082 \leq P_{\mathrm{bc}} \leq 0.085 \mathrm{MPa}\right) .
\end{aligned}
$$

Thus, $P_{\mathrm{bc}} \approx 0.0835 \mathrm{MPa}\left(\bar{\gamma}_{\mathrm{c}}=0.0096\right)$ may be regarded as a reliable estimate which, according to Equation (3.8) and data from Table 1, gives a mean Holocene air content at Vostok of $V \approx 0.088 \pm 0.0016 \mathrm{~cm}^{3} \mathrm{~g}^{-1}$. This value appears to be in good agreement with the Holocene level, i.e. $V \approx 0.0862 \pm 0.0025 \mathrm{~cm}^{3} \mathrm{~g}^{1}$ determined as the mean air content in the ice-core depth range $182.39-183.00 \mathrm{~m}$ (see Fig. 3).

As for the ice-flow law in Equation (3.1), the deduced limits of the main similarity criteria $K_{1}$ and $K_{2}$ are yet too uncertain and additional investigations are needed. Since we cannot give preference to any of the bubble-pressure profiles, either directly measured in the laboratory or derived from the air-volume concentration data, the middle curve 3 (dotted line) has been drawn in Figure $4 \mathrm{~b}$ between the best pressure fits previously found (curves 1 and 2). The model simulation of the porosity profile I at $P_{\mathrm{bc}}=$ $0.0835 \mathrm{MPa}$ results in practically the same depth distribution of the bubble pressure, as shown by curve 3 in Figure $4 \mathrm{~b}$ with $K_{1}=1.36$ and $K_{2}=0.076$. These values might be considered as most plausible. It is remarkable that they reveal obvious shifts from the mid points of the above-determined intervals. The observed asymmetry implies that the influence of $K_{1}$ and $K_{2}$ on the bubble-pressure profile is essentially non-linear with maximal sensitivity within the bands given by the least distances from the latter values of $K_{1}$ and $K_{2}$ to their bounds. This, in turn, suggests that the upper and lower estimates are somewhat exaggerated and have been overtuned by the best-fit procedure. Special computational tests fully confirm this conclusion. Actually, simulated porosity and bubble-pressure profiles cover the range between the two upper and lower limiting cases as $K_{1}$ amd $K_{2}$ cover the following narrower ranges:

$$
K_{1}=1.4 \pm 0.8, \quad K_{2}=0.092 \pm 0.04 .
$$

Using Table 1 and Equations (3.5), we can easily transform these estimates into dimensional in-situ rheological properties of Vostok ice:

$$
\begin{aligned}
& M_{1}=(2.3 \pm 1.3) \times 10^{3} \mathrm{MPa} \text { year, } \\
& M_{2}=(41 \pm 18) \mathrm{MPa}^{\alpha} \text { year } .
\end{aligned}
$$

In order to extend this result to other conditions and to compare with other available data, further validation of the model and, in particular, validation of the flow law is necessary, since we still need activation energies $Q_{1}$ and $Q_{2}$ to evaluate the factors $\mu_{1}$ and $\mu_{2}$ in Equation (3.2). 


\section{VALIDATION OF THE INFERRED ICE RHEOL- OGY AND TESTING THE MODEL ON THE OTHER ICE GORES}

Now, to verify the theory and to extend the flow law in Equations (3.1) and (3.2) of polycrystalline ice from the extreme Vostok temperature $-55^{\circ} \mathrm{C}$ to warmer situations, we use in the model in Equations (3.4)-(3.7) to simulate the air-volume-concentration profiles in bubbly ice at other Antarctic and Greenland sites.

According to earlier reviews by Budd (1969) and Shumskiy (1969) as well as to findings by Homer and Glen (1978) and Lliboutry's (1981) review, we assume $Q_{1} \approx Q_{2} \approx 60 \mathrm{~kJ} \mathrm{~mole}^{-1}$. In this framework, from the above estimates of the rheological parameters $M_{1}$ and $M_{2}$ for Vostok ice, we straightforwardly get $\mu_{1}$ and $\mu_{2}$ in Equation (3.2) at $\alpha=3.5$.

$\mu_{1}=2.9 \pm 1.3 \mathrm{MPa}$ year, $\mu_{2}=0.051 \pm 0.019 \mathrm{MPa}^{\alpha}$ year .

In order to validate the latter result, the predicted porosity variations vs depth for $\mu_{1}=2.9 \mathrm{MPa}$ year and $\mu_{2}=$ $0.051 \mathrm{MPa}^{\alpha}$ year are compared in Figure $5 \mathrm{a}-\mathrm{g}$ (solid lines) with the experimental profiles (small crosses) measured in Antarctica: at Komsomolskaya, Vostok I (Salamatin and others, 1985), Pionerskaya (Smirnov, 1983), Byrd Station (Gow, 1968a, b) and along the Mirny-Vostok route, at 60 and $105 \mathrm{~km}$ from Mirny, and in Greenland at site 3 (Langway, 1958, 1967). All the data needed for the computations are presented in Table 1 . Additional information on presentday geographic variations of the air content $V$ in recent ice (Martinerie and others, 1992) has been employed to estimate the bubble pressure $P_{\mathrm{bc}}$ at close-off depth. Actually, we used the error envelope established by Martinerie and others (1992) for the air content-elevation linear relationship as a limiting band when adjusting $P_{\mathrm{bc}}(V)$ for stations Site 2, Vostok I and Komsomolskaya for which experimental data on $V$ were not available.

All simulated curves in Figure 5 are in good agreement with the experimental porosity profiles. This result is remarkable, when considering the fact that the temperature range from $-55^{\circ} \mathrm{C}$ at Vostok to $-20^{\circ} \mathrm{C}$ at $60 \mathrm{~km}$ corresponds to a change in the rheological parameters $M_{1}$ and $M_{2}$ by more than a factor of 50 (Equations (3.1) and (3.2)). Even a $10 \%$ variation of the activation energies $Q_{1}$ and $Q_{2}$ would change the coefficients $\mu_{1}$ and $\mu_{2}$ by more than a factor of 2 . This could noticeably enlarge the discrepancy between theoretical predictions and experimental data. As an example, the two corresponding porosity profiles simulated for Site 2 conditions with the parameters $\mu_{1}$ and $\mu_{2}$ equal to those given by Equation (5.1) multiplied or divided by a factor of 2 are shown by the dashed curves in Figure $5 \mathrm{~g}$. Thus, the developed densification model and the deduced in-situ rheology of pure ice are well confirmed and can be compared now with independent data, including laboratory tests conducted on various ice samples within the same stress ranges.

Figure 6 illustrates the compatibility of the rheological properites of pure ice for low stresses and/or stresses independently derived from other experimental data from Vostok. All measurements and relations are reduced to a temperature of $-10^{\circ} \mathrm{C}$ according to Equation (3.2) at $Q_{1}=$ $Q_{2}=60 \mathrm{~kJ} \mathrm{~mole}^{-1}$ and are expressed in terms of the effective stresses $\tau$ and effective strain rates $\dot{e}$ introduced in section 3 . The flow law in Equations (3.1), (3.2) and (5.1) is depicted by
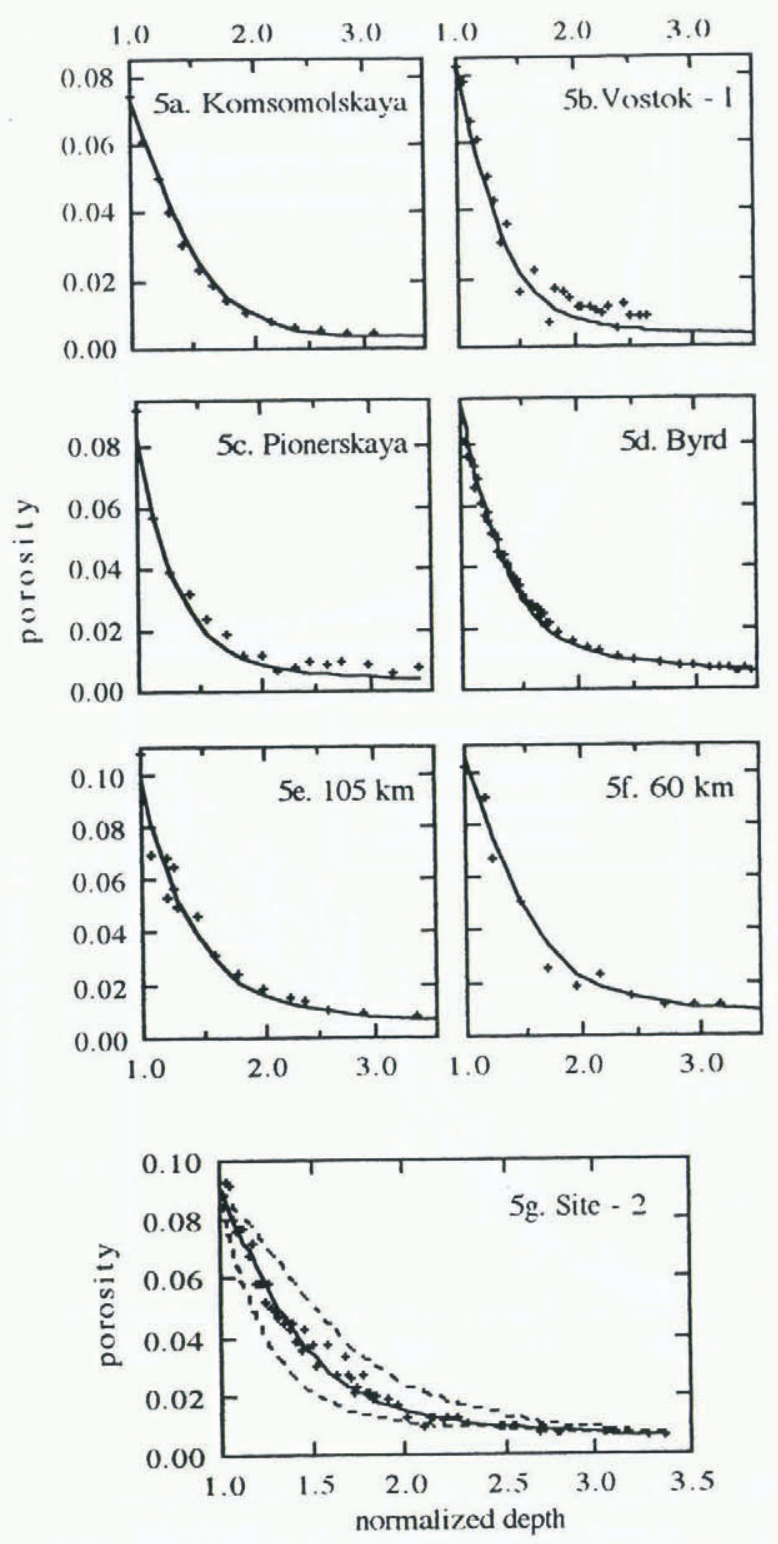

Fig. 5. Comparison of model and experimental ice-porosity profiles for seven sites in Antarctica $(a-f)$ and Greenland $(\mathrm{g})$. Solid lines are the porosity curves computed with $Q_{1}=Q_{2}=60 \mathrm{~kJ} \mathrm{~mole} e^{-1}$ for the site conditions as indicated in Table 1. The dashed lines in ( $g$ ) are the porosity profiles simulated with activation energies changed by $\pm 10 \%$ from the original values.

a thick solid line extended by the dashed line beyond the stress interval of model validation. The dotted lines are the bounds of its probable uncertainty within the stress range typical for bubbly-ice densification. The three thin lines in Figure 6 represent the earlier findings of the authors on inferring ice rheology (in the framework of a power-creep law) through an inverse procedure by modelling different natural processes in glacial ice: ice-sheet flow in East Antarctica (Salamatin and others, 1982), bubbly-ice densification at Vostok Station (Salamatin and others, 1985), the closure of the deep dry borehole at Vostok (Salamatin and others, 1981). Although the slopes of the power approximations (thin lines) in logarithmic scales differ from the slope of the flow law in Equation (3.1) deduced in this work (thick line), the average magnitudes of the strain rates within the corresponding ranges of stresses are almost the same.

Special mechanical tests have recently been carried out at $-10^{\circ} \mathrm{C}$ by Duval and Castelnau (1995) on isotropic ice- 


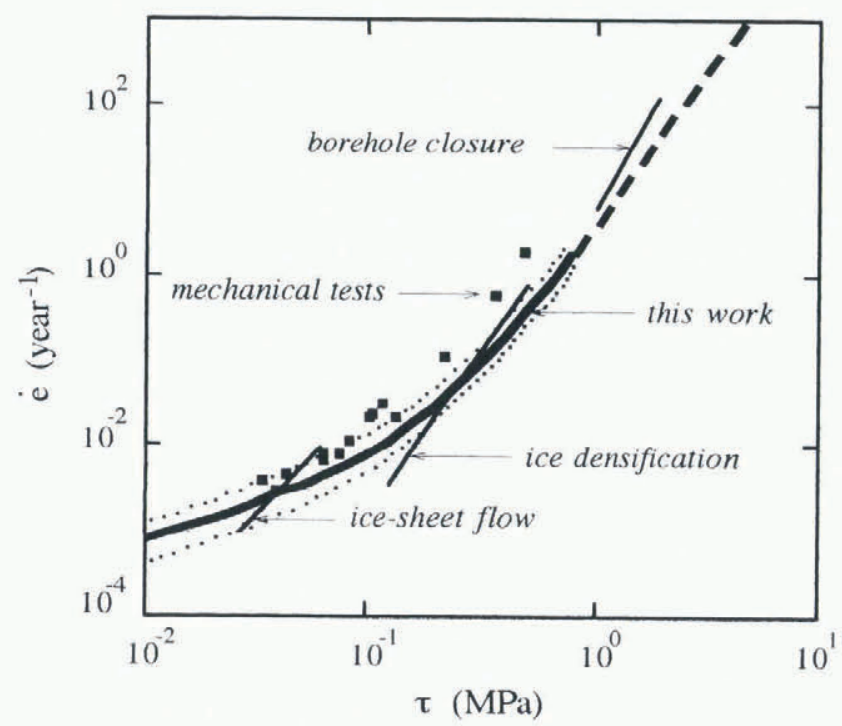

Fig. 6. Ice-flow law at $-10^{\circ} \mathrm{C}$. The thick curve is the flow law obtained in this study (the effective strain rate $\dot{e}$ is expressed as a polynomial function of the effective stress $\tau$ ). The dashed part of the thick curve represents extrapolation beyond the stress range of model validation; the envelope between the dotled lines characterizes the uncertainties of the deduced rheological law. The thin curves represent the power-creep law of ice within different stress ranges as revealed from analyses of natural process: ice-sheet flow in East Antarctica, ice densification (for the power-creep law), closure of the deep dry borehole at Vostok Station. The small squares are the data from mechanical lests on ice-core samples in a low-stress range.

core samples at comparatively low stresses within the range not covered by other investigators. These data are shown in Figure 6 as small solid squares. The principal result of the comparison is that the developed theory of bubbly-ice densification (paper I) and the deduced flow law of pure polycrystalline ice are close to reality and can be used for various applications.

\section{DISGUSSION OF THE CLIMATIC EFFEGT ON THE POROSITY PROFILE}

Another characteristic feature of the densification process will be employed to obtain information about climatically induced variations of the air content in Vostok ice in the past. Actually, it has been shown in paper I that below the level corresponding to the normalized depth $\bar{h}=3.0$ bubbly-ice densification passes into the asymptotic phase. At this stage, the rate of compression is mainly determined by the current accumulation rate (i.e. by the present-day rate of ice loading and sinking) and, what is most important, the bubble pressure for $\bar{h} \geq 3.0$ does not depend on the air content, provided that the process of ice formation was stationary during the Holocene period. The latter fact means that the profile of the bubble pressure in the deeper part of the ice sheet can be simulated at contemporary climatic conditions as an extension of the model predictions accordingly to Equations (3.4)-(3.7). Then, if the experimental data on ice porosity for the depths $\bar{h} \geq 3.0$ are available, the air content $V$ (or $\bar{\gamma}_{c}$ ) of the deep ice can be simply evaluated from Equations (3.7) and (3.8) on the basis of the porosity profile.
For small values of $c \approx 2-3 \times 10^{3}(\bar{h}>3.0)$, we have (see paper I):

$$
\bar{\gamma}_{\mathrm{c}}=c \bar{P}_{\mathrm{b}}, \quad V=c P_{\mathrm{b}} T_{\mathrm{s}} /\left(P_{\mathrm{s}} T_{\mathrm{c}} \rho_{\mathrm{i}}\right) .
$$

On the other hand, the bubble pressures reconstructed from porosity measurements at constant mean Holocene air content would deviate from the simulated ones if the real values of $V$ were different.

With this in mind, the profile of the bubble pressure simulated for the Vostok ice core in accordance with the results of section 4 has been extended down to $500 \mathrm{~m}$, i.e. until the beginning of the transition zone of air-hydrate formation (Lipenkov, 1989; Uchida and others, 1994). It is compared in Figure 7 with bubble pressure (small crosses) calculated from porosity profile I (the data from badly fractured ice samples are omitted here). The bubble pressure has been derived from Equation (3.7) under the assumption that $\bar{\gamma}_{\mathrm{c}}(V)$ is constant and equal to its mean Holocene value $\bar{\gamma}_{c}=0.0096\left(V=0.088 \mathrm{~cm}^{3} \mathrm{~g}^{-1}\right)$. As could be expected, the theoretical curve is well fitted to these data for $\bar{h} \leq 3.0$. Deeper, all crosses lie below both predicted values and direct measurements (crossed squares) of bubble pressure. This deviation is statistically significant and is thought to be an effect of climatic and/or ice-sheet elevation changes which influence the air content through close-off conditions: $c_{\mathrm{c}}, P_{\mathrm{bc}}, T_{\mathrm{c}}$. From Figure 7 , it is obvious that the air content in LGM ice is higher than the value of $0.088 \mathrm{~cm}^{3} \mathrm{~g}{ }^{-1}$ for $\mathrm{Ho}$ locene ice.

Actually, we are interested in distinguishing the variations of the air content, which do not exceed $\pm 10 \%$ with respect to the mean value $V \approx 0.09 \mathrm{~cm}^{3} \mathrm{~g}^{-1}$ (Lipenkov and others, 1993; Martinerie and others, 1994). The accuracy of the hydrostatic method which has been used for measuring profile $I$ is estimated to be of the order of $\pm 1-2 \times 10^{4}$ within the brittle zone. Therefore, in order to guarantee an error level not worse than $\pm 5-7 \%$, we should initially stop Equations $(6.1)$ at a depth of $450-500 \mathrm{~m}$, where $c \approx 1.5-2.0 \times 10^{-3}$.

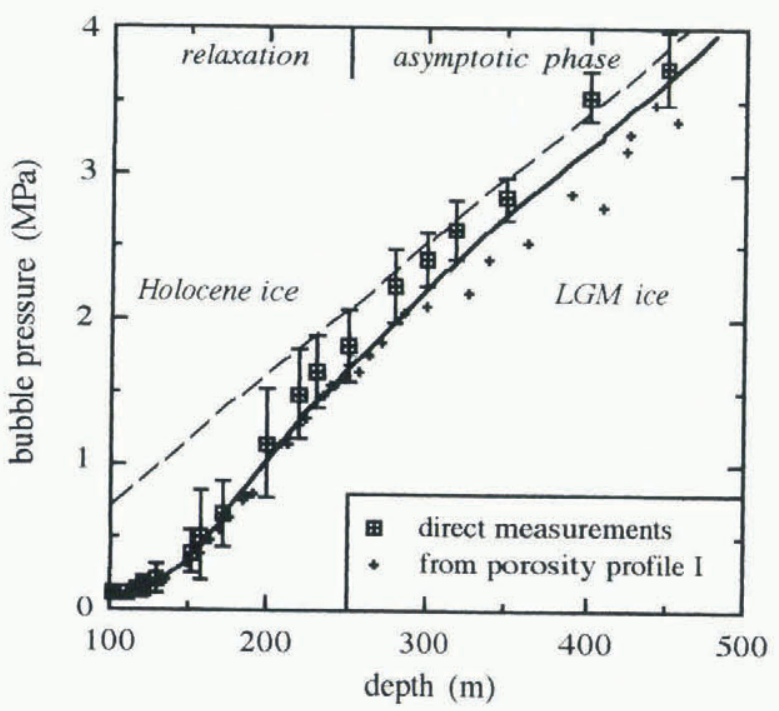

Fig. 7. Comparison of the computed bubble-pressure profile and experimental data down to the lower boundary of bubbly ice at Vostok Station. The solid curve is the theoretical profile computed for present-day close-off conditions and for the resultant rheological parameters and air content obtained for Holocene ice at Vostok. The symbols are the experimental data as indicated in the figure and explained in the text. The dashed line is the absolute load pressure. 
From this point of view, porosity profile I provides an opportunity to evaluate air-content variation in the ice down as far as at least $450 \mathrm{~m}$. Profile II is not suitable for these reconstructions, since it is approximately twice as inaccurate. In accordance with the estimates of the gas age in the Vostok ice core (Barnola and others, 1991), climatically induced variations of the air content up to 22 kyear BP, i.e. including Last Glacial Maximum, may be discovered. This is of special interest because LGM ice at Vostok Station is entirely enclosed in the brittle zone (see Fig. 1), where direct air-content measurements are extremely restricted due to the pure quality of the ice core. It should be added here that the observed fluctuations in the experimental porosity profile I cannot be explained only by probable fracturing of the ice core (even if the normal-level fissure effect on porosity is estimated to be as high as $\left.1-2 \times 10^{-4}\right)$. The main reason for this is that the systematic error of the hydrostatic method caused by the inevitable existence of micro-fissures in the deep bubbly-ice cores has already been (at least partly) eliminated by fitting the theoretical pressure and porosity profiles to the experimental data within the upper $300 \mathrm{~m}$ of the ice core. Although the Vostok ice core becomes more brittle as the depth increases, its maximal fracturing still develops within the depth interval of 400-600 m, where the energy of the compressed air in the bubbles is high, while the distance between bubbles remains short. Furthermore, the variance of the main part of the porosity record down to a depth of $500 \mathrm{~m}$ remains within $3-5 \%$.

Thus, the porosity data from the interval $300-500 \mathrm{~m}$ are straight-forwardly transformed, according to Equations (6.1), into an air content to match the predicted bubble-pressure profile. The inferred variations of the air content in the Vostok ice core with gas age (Barnola and others, 1991) are shown in Figure 8 by crosses connected by thin lines. The dashed lines correspond to the inferred mean levels of air content during the Holocene $\left(V=0.088 \pm 0.0016 \mathrm{~cm}^{3} \mathrm{~g}^{-1}\right)$

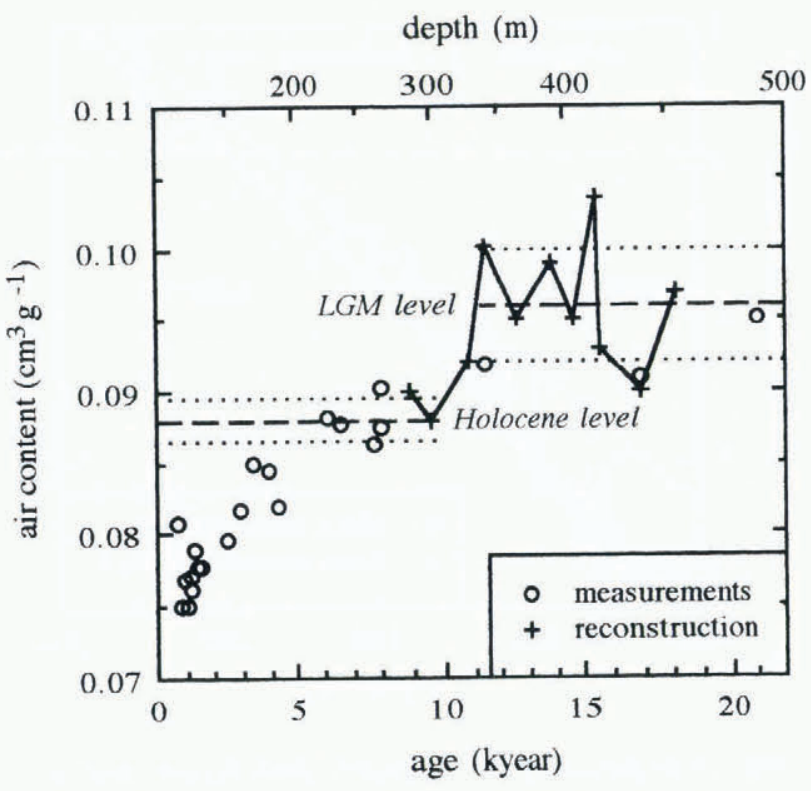

Fig. 8. Comparison of the reconstructed air-content and experimental data available for the Vostok ice core down to a depth of $500 \mathrm{~m}$. Dashed lines show the mean levels of air content in Holocene and LGM ices as deduced from interpretation of the porosity profile. Envelopes of uncertainties are shown by the dotted lines. and at the Last Glacial Maximum $(V=0.096 \pm$ $\left.0.004 \mathrm{~cm}^{3} \mathrm{~g}^{-1}\right)$. The dotted lines outline the envelope of uncertainties in these values. Direct measurements of air content (fragment of composite profile from Martinerie and others (1994) and data obtained in this study) are also plotted in Figure 8 for the objective of comparison.

Additional information on LGM air-content level in the Vostok ice core is especially desirable, because the few experimental data available for LGM ice appear to be even less precise than in the upper (Holocene) part of the Vostok air-content profile (Martinerie and others, 1994). The deduced air content in LGM is consistent, within the limits of declared uncertainties, with the scarce experimental points obtained for these depths. The new $V$ data inferred from analysis of the porosity profile in the Vostok ice core confirm the higher air content in glacial age ice than that in interglacial age ice. The amplitude of the $V$ variation associated with the climatic transition from LGM to Holocene is found to be about $9 \%$, which is very similar to the amplitude of the air-content change observed in the Vostok ice between 1900 and $2000 \mathrm{~m}$ and corresponding to the penultimate deglaciation (Martinerie and others, 1994). This change in air content may be interpreted in terms of thermal variations of the close-off porosity (Raynaud, 1983), climatically induced changes in atmospheric pressure (Gates, 1976) and thickening of the ice sheet in the Vostok region during the last deglaciation (Salamatin and Ritz, 1996).

Note that the above estimates of the air-content variations are based on the simulated bubble-pressure profile which lies systematically below the direct-pressure measurements in bubbles (see Fig. 7) within glacial age ice (i.e. deeper than $250 \mathrm{~m}$ where ice age exceeds $11-12$ kyear (Lorius and others, 1985)) and entrapped air is 5-6 kyear younger (Barnola and others, 1991). Hence, this difference between predicted and measured pressures could be at least partly due to the "softer" rheological properties of ice during LGM (Paterson, 1991). If so, then the air-content change might be even larger.

\section{CONCLUSION}

A new model of bubbly-ice densification and new experimental data have been used jointly with the aim of both identifying the model and interpreting various points concerning this process. The ice-creep law at low stresses (in the polynomial form) has been deduced and verified for a wide range of temperatures. Climatically induced air-content variations in bubbly ice at Vostok (central Antarctica) have been estimated on the basis of inverse methods and compared with direct measurements. Compatibility and good agreement between model predictions and a vast series of different data demonstrate the validity of the conducted research. At the same time, this work provides a necessary basis for deeper investigations of the air-hydrate formation process in polar ice sheets.

\section{ACKNOWLEDGEMENTS}

The authors are grateful toJ. M. Barnola, J. Meyssonnier, D. Raynaud from the Laboratoire de Glaciologie et Géophysique de l'Environnement (L.G.G.E., Grenoble), to T. Hondoh from the Institute of Low Temperature Science (Sapporo) and to K. Hutter from the Institut für Mechanik (Darm- 
stadt) for useful discussions and comments. We also thank J. R. Petit, L. Augustin and M. Maitre (L.G.G.E) for assistance in designing and preparing the equipment for the icecore study. Our special acknowledgements are addressed to P. Martinerie (L.G.G.E), who thoroughly read the draft and suggested many constructive improvements taken into account in the final version of the paper.

This research was supported in Russia by the Russian Federation State Committee for Science and Technologies and the Russian Basic Research Foundation, and in France by the Programme National d'Études de la Dynamique du Climat (C.N.R.S.), the Département Sciences Pour l'Ingénieur du C.N.R.S. and Le Congrès de Mécanique à Grenoble.

\section{REFERENCES}

Bader, H. 1964. Density of ice as a function of temperature and stress. CRREL Spec. Rep. 64.

Bader, H. 1965. Theory of densification of dry, bubbly glacier ice. CRREL Res. Rep. 141.

Barkov, N. I. and V.Ya. Lipenkov. 1984. Kolichestvennava kharakteristika struktury l'da do glubiny $1400 \mathrm{~m}$ v rayone stantsii Vostok v Antarktide [Numerical characteristics of ice structure down to a depth of $1400 \mathrm{~m}$ in the region of Vostok station, Antarctica]. Mater. Glyatsiol. Issled. 51, $178-186$.

Barnola, J. -M., P. Pimienta, D. Raynaud and Ye. S. Korotkevich. 1991. $\mathrm{CO}_{2}$-climate relationship as deduced from the Vostok ice core: a reexamination based on new measurements and on a re-evaluation of the air dating. Tellus, 43B (2), 8390.

Budd, W. 1969. The dynamics of ice masses. ANARE Sci. Rep., Ser. A (IV). Glaciology 108.

Butkovich, T. R. 1955. Density of single crystals of ice from a temperate glacier. f. Glaciol., 2 (18), 553-559.

Duval, P. and O. Castelnau. 1995. Dynamic recrystallization of ice in polar ice sheets. 7. Phys. (Paris), IV (5), Colloq. C3,197-205. (Supplément au 3.)

Gates, W. L. 1976. The numerical simulation of an ice-age climate with a global general circulation model. \%. Atmos. Sci., 33, $1844-1873$.

Gow, A. J. 1968a. Bubbles and bubble pressures in Antarctic glacier ice. F. Glaciol., 7 (50), 167-182

Gow, A. J. 1968b. Deep core studies of the accumulation and densification of snow at Byrd Station and Little America V, Antarctica. CRREL Res. Rep. 197.

Gow, A. J. and T. Williamson. 1975. Gas inclusions in the Antarctic ice sheet and their glaciological significance. 7 . Geophys. Res., 80 (36), 5101-5108.

Homer, D. R. and J.W. Glen. 1978. The creep activation energies of ice. $f$. Glaciol., 21 (85), 429-444.

Langway, C. C., Jr. 1958. Bubble pressures in Greenland glacier ice. International Association of Scientific Hydrology Publication 47 (Symposium at Chamonix 1958 - Physics of the Movement of the Ice), 336-349.

Langway, C. C., Jr. 1967. Stratigraphic analysis of a deep ice core from Greenland. CRREL Res. Rep. 77.

Lipenkov, V.Ya. 1989. Obrazovaniye i razlozheniye gidratov vozdukha v lednikovom l'du [Formation and decomposition of air hydrates in glacier ice]. Mater. Glyatsiol. Issled. 65, 58-64.

Lipenkov, V.Ya., A. N. Salamatin and Yu. A. Grigor'yeva. 1989. Matematicheskaya model' i chislennoye issledovaniye protsessa uplotneniya lednikovogo l'da [Mathematical model and numerical studies of glacier ice densification process]. Mater. Glyatsiol. Issled. 65, 49-58.
Lipenkov, V. Ya., N. I. Barkov, P. Martinerie and D. Ravnaud. 1993. Glazosoderzhaniye ledyanykh otlozheniy v rauone st. Vostok [Air content of the ice deposits near the Vostok station]. Antarktika 31, 85-98.

Lipenkov, V., F. Candaudap, J. Ravoire, E. Dulac and D. Raynaud. 1995. A new device for the measurement of air content in polar ice, f. Glaciol., 41 (138), $423-429$.

Lliboutry, L. 1981. A critical review of analytical approximate solutions for steady state velocities and temperatures in cold ice-sheets. Z. Gletscherkd. Glazialgeol., 15(2), 1979, 135-148.

Lorius, C. and 6 others. 1985. A 150,000-year climatic record from Antarctic ice. Nature, 316 (6029), 591-596.

Martinerie, P., V.Ya. Lipenkov and D. Raynaud. 1990. Correction of aircontent measurements in polar ice for the effect of cut bubbles at the surface of the sample. F. Glaciol., 36(124), 299-303.

Martinerie, P., D. Raynaud, D. M. Etheridge, J.-M. Barnola and D. Mazaudier. 1992. Physical and climatic parameters which influence the air content of polar ice. Earth Planet. Sci. Lett., 112 (1-4), 1-13.

Martinerie, P., V.Y. Lipenkov, D. Raynaud, J. Chappellaz, N. I. Barkov and C. Lorius. 1994. Air content paleo record in the Vostok ice core (Antarctica): a mixed record of climatic and glaciological parameters. 7. Geophys. Res., 99 (D5), 10,565-10,576.

Paterson, W. S. B. 1991. Why ice-age ice is sometimes "soft". Cold Reg. Sci. Technol., 20 (1), 7598.

Pimienta, P. and P. Duval. 1989. Rheology of polar glacier ice. (Abstract.) Ann. Glaciol., 12, $206-207$.

Raynaud, D. 1983. Glaciological parameters, their measurement and significance. Total gas content. In Robin, G. de Q., ed. The climatic record in polar ice sheets. Cambridge, etc., Cambridge University Press, 79-82.

Salamatin, A. N. and P. Duval. 1997. Creep flow and pressure relaxation in bubbly medium. Int. J. Solids Struct., 34 (1), 61-78.

Salamatin, A. N. and C. Ritz. 1996. A simplified multi-scale model for predicting climatic variations of the ice-sheet surface elevation in central Antarctica. Ann. Glaciol., 23, 28-35.

Salamatin, A. N., V. K. Chistyakov, D. N. Dmitriyev and V. M. Pashkevich. 1981. Teoreticheskiy analiz i eksperimental'noye issledovaniye deformatsii stenok stvola skvazhiny v ledovom massive [Theoretical analysis and experimental investigation of the well wall deformation in the ice massif]. Antarktika 20, 135-143.

Salamatin, A. N., K. Ye. Smirnov and A. N. Sheremet'yev. 1982. Primeneniye matematicheskoy modeli statsionarnogo lednika $\mathrm{k}$ raschetu termogidrodinamicheskih kharakteristik lednikovogo pokrova Antarktidy v rayone marshruta ot Mirnogo $\mathrm{k}$ kupolu B [Using the mathematical model of a stationary glacier for calculating the thermodynamic characteristics of the Antarctic ice sheet in Mirny-Dome B area]. Mater. Glyatsiol. Issled. 44, 39-49.

Salamatin, A. N., V.Ya. Lipenkov, K. Ye. Smirnov and Yu. V. Zhilova. 1985. Plotnost' lednikovogo l'da i yego reologicheskiye svoystva [The density of glacier ice and its rheological properties]. Antarktika 24, 94-106.

Salamatin, A. N., V. Ya Lipenkov and P. Duval. 1997. Bubbly ice densification in ice sheets. 1. Theory. F. Glaciol.,43 (145), 387-396

Scholander, P. F. and D. C. Nutt. 1960. Bubble pressure in Greenland icebergs. f. Glaciol., 3 (28), 671-678.

Shumskiy, P. A. 1969. Gidrologiya sushi. Glyatsiologiya. Dinamicheskaya glyatsiologiya [Land hydrology. Glaciology. Dynamic glaciology]. Itogi Nauki, Ser. Geografiya, 1, 1968.

Smirnov, K. Ye. 1983. Issledovaniya razreza lednikovogo pokrova v rayone stantsii Pionerskoy (Vostochnaya Antarktida) [Studies of the cross-section of the ice sheet in the region of Pionerskaya Station eastern Antarctica) ]. Mater. Glyatsiol. Issled. 46, $128-132$.

Uchida, T., T. Hondoh, S. Mae, V.Ya. Lipenkov and P. Duval. 1994. Airhydrate crystals in deep ice-core samples from Vostok Station, Antarctica. 7. Glaciol., 40 (134), 79-86. 